\title{
Pre-menarche adolescent girls' menstrual knowledge and preparedness to menarche in North Shewa zone of Amhara region, Ethiopia
}

Abayneh Birlie Zeru ( $\sim$ abaybrl@gmail.com )

DBU: Debre Berhan University https://orcid.org/0000-0003-1631-1498

Mikyas Arega Muluneh

DBU: Debre Berhan University

\section{Research}

Keywords: Pre-menarche adolescent girls, menstrual knowledge, preparedness to menarche, Ethiopia

Posted Date: September 15th, 2020

DOI: https://doi.org/10.21203/rs.3.rs-73097/v1

License: (c) (1) This work is licensed under a Creative Commons Attribution 4.0 International License.

Read Full License 


\section{Abstract}

Background: Many adolescent girls in Ethiopia attain menarche without adequate knowledge and preparation which could have a distressing negative impact on their psychosocial, physical, and emotional wellbeing. This study aimed to assess pre-menarche adolescent girls' menstrual knowledge and preparedness to menstruation and associated factors in the North Shewa Zone of the Amhara region.

Methods: A school-based cross-sectional study was conducted on participants selected through a multistage sampling technique. Data collected through a self-administered questionnaire were entered into Epi Data and exported to SPSS for analysis. Bi-variable and multivariable logistic regressions were computed to identify factors associated with the good menstrual knowledge and preparedness to menarche. An odds ratio with $95 \% \mathrm{Cl}$ was computed to measure the magnitude of the association. Variables with a pvalue of $<0.05$ on multivariable analysis were considered statistically significant factors associated with the outcome variable.

Results: From a total of 424 pre-menarche adolescent girls included in the study, 166(39.2\%) had good menstrual knowledge and about a quarter $110(25.9 \%)$ had good preparedness towards menarche. An increase in the school grade level of adolescent girls, the educational status of the mother, and occupation of the father (government employment) were positively associated with good menstrual knowledge. Having good menstrual knowledge increased the preparedness of pre-menarche girls to menarche by over 13 -fold than poorly knowledgeable girls.

Conclusions: Menstrual knowledge and preparedness to menarche of pre-menarche adolescent girls were low in the North Shewa Zone of the Amhara region. The level of preparedness to menarche was also highly dependent on girls' menstrual knowledge. Thus, the school's health program and teachers should address the problem by delivering age-appropriate menstrual information to equip adolescent girls with accurate and adequate menstrual knowledge before the onset of menarche.

\section{Plain English Summary}

Many adolescent girls in Ethiopia experience their first menstruation without adequate knowledge and preparation which could have a distressing negative impact on their future life. This study assessed menstrual knowledge and preparedness for menstruation and associated factors of adolescent girls who not ever had menstruation in the North Shewa Zone of the Amhara region. Data were collected from 424 non-menstruating adolescent female students selected from primary and secondary schools found both in urban and rural areas. We found that $166(39.2 \%)$ had good knowledge about menstruation and $110(25.9 \%)$ had better preparedness for their first menstruation. Those girls' knowledge about menstruation and preparedness for the first menstruation was low in the North Shewa Zone of the Amhara region. The level of preparedness to first menstruation was highly reliant on girls' menstrual knowledge. Thus, the school's health program and teachers should address the problem by delivering 
age-appropriate menstrual information to equip adolescent girls with accurate and adequate menstrual knowledge before the onset of menarche.

\section{Introduction}

Adolescence is a period of transition from childhood to adulthood characterized by rapid physical, psychological, and mental development and maturity. It is also the time of rapid development of secondary sexual characteristics including the initiation of menstruation for girls. Menstruation is the physiological process of releasing blood from the uterus through the vagina as part of the menstrual cycle experienced by adolescent girls and women in reproductive age $(1-3)$. This is the periodic shedding of the inner lining of endometrium, which was prepared to support the growth of the fertilized egg, in the absence of fertilization of egg with sperm. The onset of menstruation for the first time is known as menarche, which usually occurs during early adolescence (10-14 years of age) (4).

Although menstruation is a natural phenomenon, it is surrounded by socio-cultural and religious beliefs and taboos in low and middle-income countries (LMICs) including Ethiopia. Because of these harmful beliefs and taboos, menstruation is considered as embarrassing, shameful and something that has to be hidden which restrict adolescent girls to discuss menstruation and reproductive health with their parents or other family members, friends and teachers. These restrictions create barriers to access accurate and comprehensive information about menstruation and related hygienic management for adolescent girls. This in turn leads to a misconception of adolescent girls about menstruation $(1,2,5-7)$.

As a result, a substantial number of adolescent girls in LMICs attain menarche without adequate knowledge and preparation about menstruation and its hygienic management $(1,5,8)$. Studies in India (9), Gambia (10) and Benin (11) revealed that less than two-thirds of girls were informed about menstruation before its occurrence and most of them felt unprepared for menarche. Unpreparedness was more frequently reported by girls who experienced menarche at a relatively early age. In Ethiopia, the proportion of adolescent girls who had menstrual knowledge before menarche ranges from $27.1-51.4 \%$ $(7,12-14)$.

In addition to harmful beliefs and taboos in the community, for adolescent girls who lack knowledge and unpreparedness to menstruation, menarche will be a distressing experience of fear, anxiety, embarrassment, tension, and shame $(9,11,12,15,16)$. Inability to manage menstruation with dignity in public spaces like schools intensifies these feelings and increase school absenteeism, school dropout, and poor academic performance of adolescent girls $(1,5,17)$. On the other hand, good menstrual knowledge and preparation for menstruation before menarche effectively improves positive experience to menarche, attitude towards menstruation, and proper menstrual hygienic practice $(13,18,19)$. Thus, menarche is one of the most crucial sudden events of adolescent girls which potentially might profound negative impact on the psychosocial, physical, and emotional wellbeing of adolescent girls and their future lives $(1,6,15)$. 
Almost all local studies in Ethiopia were focused on menstrual hygiene management and few of them addressed menstrual knowledge and preparedness before menarche by measuring it retrospectively on post-menarche adolescent girls. As the evidence showed, most adolescent girls considered menarche as a triggering factor to learn about menstruation (1). This knowledge learned after menarche and their menstrual experience could affect their response leading to the overestimation of menstrual knowledge and preparedness to menstruation before menarche. Therefore, this study aimed to assess pre-menarche adolescent girls' menstrual knowledge and preparedness to menstruation and associated factor in North Shewa zone of Amhara region, Central Ethiopia

\section{Methods}

\section{Study setting and period}

The study was conducted from January 16, 2019, to March 30, 2019, in North Shewa zone. North Shewa zone is one of the eleven zones found in the Amhara national regional state of Ethiopia. The zone is divided into twenty-four woreda and three town administrations. Debre Birhan is zonal administrative town of North Shewa zone which is $130 \mathrm{~km}$ northeast of the capital city Addis Ababa at latitude of $9^{\circ} 46^{\prime} 8.4^{\prime \prime} \mathrm{N}$ and longitude $39^{\circ} 40^{\prime} 4.8^{\prime \prime} \mathrm{E}$.

\section{Study design and population}

An institute based cross-sectional study was conducted among pre-menarche adolescent school girls. Pre-menarche adolescent female students from grade 5 to 10 who attended education at public school were our study population. Those students found from grade 5 to 10 but aged less than 10 years or greater than 19 years were excluded from the study. Similarly, students with visual or hearing impairment and from private schools were not involved in this study.

\section{Sample size and sampling procedure}

We used Epi Info version 7.1.5.0 software to determine the required sample size. The sample size for descriptive study on Epi Info was computed by considering the following assumptions: source population of the study less than $10,000,77.1 \%$ prevalence of menstrual knowledge of adolescent girls before menarche (20), $5 \%$ confidence limits, $95 \%$ confidence level and 1.5 design effect for a single cluster. From the computed value of 407 by adding a $10 \%$ non-response rate we got 448 as the final sample size. A multistage sampling technique was employed to get these study participants. First, we selected four woreda administrations (Debre Sina, Basona Werena, Hagere Mariam, and Jiru Enuari) through the lottery method. Second, we chose three schools, each from rural 2nd cycle primary schools (grade 5-8), urban 2nd cycle primary schools, and high schools (grade 9-10) randomly using lottery method to include a total of 12 schools in the study. Finally, study participants were selected by proportionate systematic random sampling after listing out of all pre-menarche adolescent girls from those schools.

\section{Data collection procedures and tools}

Data were collected using a semi-structured self-administered questionnaire. The questionnaire was developed by reviewing different pieces of literature and contextually adapted to the socio-cultural norms 
of the area. The questionnaire was divided into three sections designed to assess pre-menarche adolescent girls' socio-demographic characteristics, menstrual knowledge, and preparedness to menarche. Selected students were appointed to come back to school on the class free time of the next day for data collection. At the same time, those consent minors ( $\leq 15$ years of age) were informed to get oral consent from their parents. Data collectors instruct study participants on how to fill the questionnaire and facilitate the data collection process. The questionnaire took on average 20-25 minutes.

Knowledge of pre-menarche adolescent girls about menstruation was measured used a series of closeended 10-item questions developed after reviewing related literature $(5,10,18,21,22)$ and by consulting senior researchers who were more familiar to the area. Each correct response got one mark whereas any wrong or don't know response got no mark. The sum score of knowledge questions was calculated out of 10 points. Those who scored $\geq 7$ were categorized as having good knowledge about menstruation.

The preparedness of pre-menarche adolescent girls was measured with 8-item questions. The response of each item was scored as " 1 " for correct response and " 0 " for wrong or don't know responses. The total sum score of the tool ranges from 0 to 8 and those who scored $\geq 5$ were considered as well prepared for menarche.

\section{Data quality assurance}

The questionnaire, which was initially prepared in the English language, was translated to local (Amharic) language then re-translated back to English to check its consistency. The Amharic version of the questionnaire was pre-tested on $5 \%$ of the study subjects to ensure its understandability, internal consistency and ability to address the study objectives. According to the pre-test result, few modifications to the expression of terminologies were made. Besides, the internal consistency (reliability) of items in the menstrual knowledge and preparedness measurement tools was determined using Cronbach's alpha. It was 0.626 and 0.561 for knowledge and preparedness measurement tools. A one-day training about the objective of the study, methods of participant selection and data collection tool, and procedure for four female data collectors and one supervisor. Daily monitoring and supervision of the data collection, checking for completeness and consistency of collected data was carried out by supervisors. The principal investigator also examined the collected data for completeness and consistency before data entry.

\section{Data analysis procedures}

Collected data were entered Epi Data version 3.1 software and exported to SPSS version 24 for analysis. Both descriptive and analytical statistics were performed and presented using tables and graphs. Variables found to have a $p$-value of $<0.2$ on bi-variable analysis were included in the multivariable binary logistic regression analysis. Multivariable binary logistic regression analyses were carried out to identify socio-demographic factors associated with menstrual knowledge and to see the effect of menstrual knowledge on preparedness to menarche of pre-menarche adolescent girls. Odds ratios with $95 \%$ confidence intervals were computed and a $p$-value of $<0.05$ was used to declare the presence of a statistically significant association between the covariates and dependent variable. 


\section{Results}

\section{Demographic profile of study participants}

Out of 448 pre-menarche adolescent girls selected for study, 424 were involved in this study giving the response rate of $94.6 \%$. Table 1 demonstrates the demographic characteristics of the study participants. The mean $( \pm S D)$ age of study participants was $13( \pm 1.4)$ years. Adolescent girls aged $10-14$ years were $358(84.4 \%)$, while 64 (15.6\%) were 15-19 years of age. Most 380 (89.6\%) and 402 (94.8\%) participants were grade 5-8 students and orthodox religion followers respectively. Regarding parents' educational status, $136(34.0 \%)$ mothers and 60 (14.9\%) fathers were illiterate. Majority 242 (58.5\%) of mothers were housewives and $300(74.3 \%)$ of fathers were farmers. The mean ( \pm SD) family size of study participants was $4.9( \pm 1.6)$ (Table 1). 
Table 1

Socio-demographic characteristics of study participants in the North Shewa Zone, $2019(\mathrm{n}=424)$.

\begin{tabular}{|c|c|c|c|}
\hline \multicolumn{2}{|l|}{ Variables } & \multirow{2}{*}{$\begin{array}{l}\text { Frequency } \\
358\end{array}$} & \multirow{2}{*}{$\begin{array}{l}\text { Percent (\%) } \\
84.4\end{array}$} \\
\hline Age & $10-14$ years & & \\
\hline & $15-19$ years & 66 & 15.6 \\
\hline \multirow[t]{2}{*}{ School type } & Elementary school & 380 & 89.6 \\
\hline & High school & 44 & 10.4 \\
\hline \multirow[t]{6}{*}{ Grade } & Grade 5 & 124 & 29.2 \\
\hline & Grade 6 & 98 & 23.1 \\
\hline & Grade 7 & 100 & 23.6 \\
\hline & Grade 8 & 58 & 13.7 \\
\hline & Grade 9 & 34 & 8.0 \\
\hline & Grade 10 & 10 & 2.4 \\
\hline \multirow[t]{2}{*}{ Residence } & Rural & 258 & 60.8 \\
\hline & Urban & 166 & 39.2 \\
\hline \multirow[t]{3}{*}{ Religion } & Orthodox & 402 & 94.8 \\
\hline & Muslim & 15 & 3.5 \\
\hline & Protestant & 7 & 1.7 \\
\hline \multirow[t]{2}{*}{ Ethnicity } & Amhara & 414 & 99.5 \\
\hline & Oromo & 2 & 0.5 \\
\hline \multirow[t]{2}{*}{ Household head } & Male & 322 & 77.8 \\
\hline & Female & 92 & 22.2 \\
\hline \multirow[t]{4}{*}{ Mother's education } & Illiterate & 136 & 34.0 \\
\hline & Primary school & 228 & 57.0 \\
\hline & Secondary school & 16 & 4.0 \\
\hline & College and above & 20 & 5.0 \\
\hline \multirow[t]{3}{*}{ Father's education } & Illiterate & 60 & 14.9 \\
\hline & Primary school & 280 & 69.7 \\
\hline & Secondary school & 38 & 9.5 \\
\hline
\end{tabular}




\begin{tabular}{|c|c|c|c|}
\hline \multicolumn{2}{|l|}{ Variables } & \multirow{2}{*}{$\begin{array}{l}\text { Frequency } \\
24\end{array}$} & \multirow{2}{*}{$\begin{array}{l}\text { Percent (\%) } \\
6.0\end{array}$} \\
\hline & College and above & & \\
\hline \multirow[t]{6}{*}{ Mother's occupation } & Housewife & 242 & 58.5 \\
\hline & Farmer & 80 & 19.3 \\
\hline & Merchant & 46 & 11.1 \\
\hline & Government employee & 24 & 5.8 \\
\hline & Private employee & 18 & 4.3 \\
\hline & Others & 4 & 1.0 \\
\hline \multirow[t]{5}{*}{ Father's occupation } & Farmer & 300 & 74.3 \\
\hline & Government employee & 44 & 10.9 \\
\hline & Merchant & 38 & 9.4 \\
\hline & Private employee & 10 & 2.5 \\
\hline & Others & 12 & 3.0 \\
\hline \multirow[t]{2}{*}{ Family size } & $\leq 4$ & 156 & 36.8 \\
\hline & $>4$ & 268 & 63.2 \\
\hline
\end{tabular}

\section{Menstrual knowledge of pre-menarche adolescent girls}

Based on the 10-items questions used to measure menstrual knowledge, 166 (39.2\%) pre-menarche adolescent girls had good menstrual knowledge and 258 (60.8\%) had poor menstrual knowledge. Over two-third 292 (68.9\%) of pre-menarche adolescent girls heard of menstruation form various sources. School teachers $108(37.0 \%)$ and mothers 100 (34.2\%) were frequently mentioned primary source of information. Over half 214 (50.5\%), 232 (54.7\%), and 221 (52.1\%) pre-menarche adolescent girls knew the common age of menarche, average length of a menstrual cycle and average duration menstrual blood flow respectively. Over two-third 296 (69.8\%) recognized that menstruation is unique to females and 214 $(50.5 \%)$ considered it as sign of sexual maturity. Nearly half $210(49.5 \%)$ pre-menarche adolescent girls did not knew the cause of menstruation, while 118 (27.8\%) and 28 (6.6\%) mentioned biological process and hormonal effect as the cause of menstruation respectively. Regarding the origin of menstrual blood; $121(28.7 \%)$ said uterus, 203 (48.1\%) abdomen, and 67 (15.9\%) didn't knew (Table 2). 
Table 2

Menstrual knowledge of study participants in the North Shewa Zone, $2019(n=424)$.

\begin{tabular}{|c|c|c|c|}
\hline Variables & & Frequency & Percent (\%) \\
\hline \multirow[t]{2}{*}{ Heard about menstruation before } & Yes & 292 & 68.9 \\
\hline & No & 132 & 31.1 \\
\hline \multirow[t]{3}{*}{ Menstruation is a natural phenomenon? } & Yes & 146 & 34.4 \\
\hline & No & 226 & 53.3 \\
\hline & Don't know & 52 & 12.3 \\
\hline \multirow[t]{6}{*}{ Cause of menstruation } & Biological & 118 & 27.8 \\
\hline & Hormonal & 28 & 6.6 \\
\hline & Disease & 8 & 1.9 \\
\hline & Curse of god & 48 & 11.3 \\
\hline & Don't know & 210 & 49.5 \\
\hline & Others & 12 & 2.8 \\
\hline \multirow[t]{5}{*}{ Source organ of menstrual blood } & Uterus & 121 & 28.7 \\
\hline & Abdomen & 203 & 48.1 \\
\hline & Vagina & 26 & 6.2 \\
\hline & Don't know & 67 & 15.9 \\
\hline & Others & 5 & 1.2 \\
\hline \multirow[t]{3}{*}{ Common age of menarche } & $10-15$ years & 214 & 50.5 \\
\hline & Don't know & 188 & 44.3 \\
\hline & Others & 22 & 5.2 \\
\hline \multirow[t]{3}{*}{ Average duration of a menstruation cycle } & $21-35$ days & 232 & 54.7 \\
\hline & Don't know & 173 & 40.8 \\
\hline & Others & 19 & 4.5 \\
\hline \multirow[t]{3}{*}{ Average duration of menstrual flow } & 4-7 days & 221 & 52.1 \\
\hline & Don't know & 180 & 42.5 \\
\hline & Others & 23 & 5.4 \\
\hline \multirow[t]{2}{*}{ Menstruation is sign of sexual maturity } & Yes & 214 & 50.5 \\
\hline & No & 184 & 43.4 \\
\hline
\end{tabular}




\begin{tabular}{|llll|}
\hline Variables & & Frequency & Percent (\%) \\
\hline Menstruation is unique to females & Don't know & 26 & 6.1 \\
\hline Can pregnant women menstruate & Yes & 296 & 69.8 \\
\cline { 2 - 4 } & No & 128 & 30.2 \\
\hline Primary source of information about menstruation & Yes & 98 & 23.1 \\
\cline { 2 - 4 } & No & 304 & 71.7 \\
\cline { 2 - 4 } & Don't know & 22 & 5.2 \\
\cline { 2 - 4 } & Mother & 100 & 34.2 \\
\cline { 2 - 4 } & Elder sister & 54 & 18.5 \\
\cline { 2 - 4 } & School teacher & 108 & 37.0 \\
\cline { 2 - 4 } & Mass media & 16 & 5.5 \\
\cline { 2 - 4 } & others & 14 & 4.8 \\
\hline Level of menstrual knowledge & Good & 166 & 39.2 \\
\cline { 2 - 4 } & Poor & 258 & 60.8 \\
\cline { 2 - 4 } & & & \\
\hline
\end{tabular}

\section{Preparedness to menarche}

A large proportion of pre-menarche adolescent girls 249 (58.7\%) didn't feel they are prepared for menarche. Hundred sixty-seven (39.4\%) thought they knew what to do at the time of menarche, and 132 (31.1\%) believed they knew what to do if they start to see menarche at school. About one-fourth (24.1\%) participants considered telling someone when they experience menarche. Only one of ten pre-menarche adolescent girls (10.4\%) was willing to ask help from school teachers if menarche started while at school. Over half $228(54.3 \%)$ and $215(50.7 \%)$ of the study participants heard about menstrual hygiene management and disposable sanitary pads respectively. However, $113(26.7 \%)$ of participants believed they knew how to use absorbent materials during menstruation. From 102 participants who considered telling to someone when they experience menarche, majority 57 (55.9\%) preferred mothers followed by 25 $(24.5 \%)$ sisters and $11(10.8 \%)$ friends. Generally, only a quarter $110(25.9 \%)$ of study participants had good preparedness towards menarche (Table 3 ). 
Table 3

Preparedness to menarche of study participants in the North Shewa Zone, $2019(n=424)$.

\begin{tabular}{|c|c|c|c|}
\hline Variables & & Frequency & $\begin{array}{l}\text { Percent } \\
\text { (\%) }\end{array}$ \\
\hline \multirow[t]{2}{*}{ Do you feel prepared for menarche? } & Yes & 175 & 41.3 \\
\hline & No & 249 & 58.7 \\
\hline \multirow[t]{2}{*}{ Do you know what to do at time of menarche? } & Yes & 167 & 39.4 \\
\hline & No & 257 & 60.6 \\
\hline \multirow[t]{2}{*}{ Do you know what to do if menarche starts at school? } & Yes & 132 & 31.1 \\
\hline & No & 292 & 68.9 \\
\hline \multirow[t]{2}{*}{ Will you tell someone about your menarche? } & Yes & 102 & 24.1 \\
\hline & No & 322 & 75.9 \\
\hline \multirow{2}{*}{$\begin{array}{l}\text { Will you ask your teachers for help if menarche starts at } \\
\text { school? }\end{array}$} & Yes & 44 & 10.4 \\
\hline & No & 380 & 89.6 \\
\hline \multirow[t]{2}{*}{ Have you heard about menstrual hygiene management? } & Yes & 228 & 54.3 \\
\hline & No & 192 & 45.7 \\
\hline \multirow[t]{2}{*}{ Have you heard about disposable sanitary pads? } & Yes & 215 & 50.7 \\
\hline & No & 209 & 49.3 \\
\hline \multirow{2}{*}{$\begin{array}{l}\text { Do you think you know how to use sanitary pads or } \\
\text { clothes? }\end{array}$} & Yes & 113 & 26.7 \\
\hline & No & 309 & 73.2 \\
\hline \multirow{5}{*}{$\begin{array}{l}\text { Primary source of information about disposable sanitary } \\
\text { pads }\end{array}$} & Mother & 66 & 30.7 \\
\hline & Sister & 32 & 14.9 \\
\hline & Teacher & 82 & 38.1 \\
\hline & Friends & 19 & 8.8 \\
\hline & $\begin{array}{l}\text { Mass } \\
\text { media }\end{array}$ & 16 & 7.4 \\
\hline \multirow[t]{5}{*}{ Preference to discuss about your menarche } & Mother & 57 & 55.9 \\
\hline & Sister & 25 & 24.5 \\
\hline & Relatives & 7 & 6.9 \\
\hline & Friend & 11 & 10.8 \\
\hline & Others & 2 & 1.9 \\
\hline
\end{tabular}




\begin{tabular}{|llll|}
\hline Variables & Frequency & $\begin{array}{l}\text { Percent } \\
\text { (\%) }\end{array}$ \\
\hline Preparedness to menarche & Good & 110 & 25.9 \\
\cline { 2 - 4 } & Poor & 314 & 74.1 \\
\hline
\end{tabular}

\section{Demographic factors associated with menstrual knowledge}

Pre-menarche adolescent girls' school grade level, educational status of the mother, and occupation of the father were significantly associated with good menstrual knowledge. Menstrual knowledge of adolescent girls increased as their school grade level increases. For a unit increase in the school grade, pre-menarche adolescent girls' menstrual knowledge increased by the odds of 1.6 [AOR; 1.631 and 95\% Cl; (1.331-1.999)]. As compared to girls of illiterate mothers, those girls whose mothers had primary school education had two-fold higher menstrual knowledge [AOR; 2.104 and $95 \% \mathrm{Cl} ;(1.261-3.510)$ ]. Adolescent girls of government-employed fathers were nearly 4 times more knowledgeable than those whose fathers were farmers [AOR; 3.978 and 95\% $\mathrm{Cl} ;(1.639-9.655)$ ] (Table 4). 
Table 4

Factors associated with menstrual knowledge in the North Shewa Zone, 2019.

\begin{tabular}{|c|c|c|c|c|c|}
\hline \multirow[t]{2}{*}{ Variables } & & \multicolumn{2}{|c|}{$\begin{array}{l}\text { Menstrual } \\
\text { Knowledge }\end{array}$} & \multirow[t]{2}{*}{$\operatorname{coR}(95 \% \mathrm{Cl})$} & \multirow[t]{2}{*}{ AOR(95\%Cl) } \\
\hline & & Good & Poor & & \\
\hline Grade & & 166 & 256 & $\begin{array}{l}1.370(1.180- \\
1.590)\end{array}$ & $\begin{array}{l}1.631(1.331- \\
1.999)^{\star}\end{array}$ \\
\hline \multirow[t]{2}{*}{ Age } & $\leq 14$ years & 138 & 220 & 1 & 1 \\
\hline & $>14$ years & 28 & 32 & $\begin{array}{l}1.395(0.805- \\
2.418)\end{array}$ & $\begin{array}{l}0.865(0.352- \\
1.449)\end{array}$ \\
\hline \multirow[t]{2}{*}{ Residence } & Rural & 88 & 170 & 1 & 1 \\
\hline & Urban & 78 & 88 & $\begin{array}{l}1.712(1.149- \\
2.552)\end{array}$ & $\begin{array}{l}1.088(0.666- \\
3.158)\end{array}$ \\
\hline \multirow{4}{*}{$\begin{array}{l}\text { Education of the } \\
\text { mother }\end{array}$} & Illiterate & 42 & 94 & 1 & 1 \\
\hline & Primary school & 98 & 130 & $\begin{array}{l}1.687(1.077- \\
2.642)\end{array}$ & $\begin{array}{l}2.104(1.261- \\
3.510)^{\star}\end{array}$ \\
\hline & $\begin{array}{l}\text { Secondary } \\
\text { school }\end{array}$ & 8 & 8 & $\begin{array}{l}2.238(0.787- \\
6.366)\end{array}$ & $\begin{array}{l}2.951(0.926- \\
9.405)\end{array}$ \\
\hline & $\begin{array}{l}\text { College and } \\
\text { above }\end{array}$ & 12 & 8 & $\begin{array}{l}3.357(1.278- \\
8.818)\end{array}$ & $\begin{array}{l}1.769(0.524- \\
5.968)\end{array}$ \\
\hline \multirow{5}{*}{$\begin{array}{l}\text { Occupation of the } \\
\text { father }\end{array}$} & Farmer & 108 & 192 & 1 & 1 \\
\hline & Merchant & 16 & 22 & $\begin{array}{l}1.293(0.651- \\
2.567)\end{array}$ & $\begin{array}{l}1.587(0.684- \\
3.679)\end{array}$ \\
\hline & $\begin{array}{l}\text { Gov't } \\
\text { employee }\end{array}$ & 24 & 20 & $\begin{array}{l}2.133(1.127- \\
4.040)\end{array}$ & $\begin{array}{l}3.978(1.639- \\
9.655)^{\star}\end{array}$ \\
\hline & $\begin{array}{l}\text { Private } \\
\text { employee }\end{array}$ & 4 & 6 & $\begin{array}{l}1.185(0.327- \\
4.292)\end{array}$ & $\begin{array}{l}1.775(0.422- \\
7.466)\end{array}$ \\
\hline & Others & 4 & 8 & $\begin{array}{l}0.889(0.262- \\
3.020)\end{array}$ & $\begin{array}{l}0.913(0.239- \\
3.492)\end{array}$ \\
\hline
\end{tabular}

\section{Effect of menstrual knowledge on preparedness to menarche}

After controlling socio-demographic confounders on multivariable analysis, menstrual knowledge was strong association with preparedness for menarche. Having good menstrual knowledge increased preparedness to menarche by over 13 -folds [AOR; 13.050 and $95 \% \mathrm{Cl} ;(6.963-24.457)]$. Besides, preparedness to menarche increased by odds of 1.8 for a unit increase in the school grade level of pre- 
menarche girls $[\mathrm{AOR}=1.804,95 \% \mathrm{Cl}(1.240-2.624)]$. As compared to girls of housewife mothers, those girls of government-employed mothers had 7.7 times higher odds of preparedness to menarche [AOR = $7.708,95 \% \mathrm{Cl}(2.421-24.537)]$ (Table 5).

Table 5

Factors associated with preparedness to menarche in the North Shewa Zone, 2019.

\begin{tabular}{|c|c|c|c|c|c|}
\hline \multirow[t]{2}{*}{ Variables } & & \multicolumn{2}{|c|}{$\begin{array}{l}\text { Preparedness to } \\
\text { menarche }\end{array}$} & \multirow[t]{2}{*}{$\operatorname{COR}(95 \% \mathrm{Cl})$} & \multirow[t]{2}{*}{$\operatorname{AOR}(95 \% \mathrm{Cl})$} \\
\hline & & Good & Poor & & \\
\hline Age & & 166 & 256 & $\begin{array}{l}1.239(1.062- \\
1.445)\end{array}$ & $\begin{array}{l}0.940(0.682- \\
1.298)\end{array}$ \\
\hline Grade & & 166 & 256 & $\begin{array}{l}1.546(1.310- \\
1.824)\end{array}$ & $\begin{array}{l}1.804(1.240- \\
2.624)^{\star}\end{array}$ \\
\hline \multirow[t]{2}{*}{ School type } & $\begin{array}{l}\text { Primary } \\
\text { school }\end{array}$ & 88 & 290 & 1 & 1 \\
\hline & High school & 22 & 24 & $\begin{array}{l}3.021(1.616- \\
5.648)\end{array}$ & $\begin{array}{l}1.047(0.372- \\
2.948)\end{array}$ \\
\hline \multirow{5}{*}{$\begin{array}{l}\text { Occupation of the } \\
\text { father }\end{array}$} & Housewife & 56 & 186 & 1 & 1 \\
\hline & Farmer & 16 & 64 & $\begin{array}{l}0.830(0.445- \\
1.550)\end{array}$ & $\begin{array}{l}0.476(0.211- \\
1.074)\end{array}$ \\
\hline & Merchant & 18 & 28 & $\begin{array}{l}2.135(1.100- \\
4.144)\end{array}$ & $\begin{array}{l}2.167(0.926- \\
5.071)\end{array}$ \\
\hline & $\begin{array}{l}\text { Gov't } \\
\text { employee }\end{array}$ & 12 & 12 & $\begin{array}{l}3.321(1.414- \\
7.803)\end{array}$ & $\begin{array}{l}7.708(2.421- \\
24.537)^{\star}\end{array}$ \\
\hline & $\begin{array}{l}\text { Private } \\
\text { employee }\end{array}$ & 2 & 6 & $\begin{array}{l}0.415(0.093- \\
1.861)\end{array}$ & $\begin{array}{l}0.469(0.084- \\
2.607)\end{array}$ \\
\hline \multirow[t]{2}{*}{ Family size } & $\leq 4$ & 30 & 116 & 1 & 1 \\
\hline & $>4$ & 76 & 182 & $\begin{array}{l}1.615(0.997- \\
2.616)\end{array}$ & $\begin{array}{l}1.719(0.910- \\
3.244)\end{array}$ \\
\hline \multirow{2}{*}{$\begin{array}{l}\text { Menstrual } \\
\text { knowledge }\end{array}$} & Poor & 18 & 240 & 1 & 1 \\
\hline & Good & 92 & 74 & $\begin{array}{l}16.577(9.389- \\
29.265)\end{array}$ & $\begin{array}{l}13.50 .963- \\
24.457)^{\star}\end{array}$ \\
\hline
\end{tabular}


Menstruation is surrounded by taboos and cultural beliefs which consider menstruation as an embarrassing, shameful, and secret thing that restrict adolescent girls to discuss it freely. This limit adolescent girls from accessing accurate information about menstruation and a significant number of adolescent girls experience menarche with poor knowledge and misconception about menstruation (1, 2, $6,7,15,22,23)$. This study finding also indicated a similar result that $39.2 \%$ of pre-menarche adolescent girls had good general knowledge and $60.8 \%$ had poor knowledge about menstruation. Misconception about specific areas of menstruation was common like $48.1 \%$ and $6.2 \%$ of adolescent girls thought that menstrual blood originates from the abdomen and vagina respectively. Nearly one-fourth $(23.1 \%)$ believed menstruation during pregnancy and $11.4 \%$ thought menstruation is caused by the curse of God.

The magnitude of $39.2 \%$ good knowledge about menstruation in this study is in line with $39.4 \%$ report in central India (24) but slightly higher than $31.7 \%$ and $31.4 \%$ report in Gedeo district of Southern Nations, Nationalities and Peoples' Regional states of Ethiopia (13) and Tumkur, India (25). This study finding is lower than $77.1 \%, 70.9 \%$, and $51.4 \%$ study reports in Adama (20), Boset (26), and Harbu (14) districts of Ethiopia respectively. Studies in Rajasthan India (9) and Benin (11) also reported that $66 \%$ and $60.7 \%$ of adolescent girls had menstrual knowledge before menarche. This disagreement between those studies might be because of the difference in the definition of menstrual knowledge and the tool used to measure it. The difference in study participants' menstrual status at the time of investigation might also have an important role in the observed inconsistency. A study in the rural Gambia (10) revealed that $26.6 \%$ and $66.0 \%$ pre-menarche and post-menarche adolescent girls had good menstrual knowledge which indicates menarche is a triggering factor for girls to learn about menstruation. The knowledge and experience after menarche of post-menarche girls could affect their response to questions related to menstrual knowledge before menarche. Therefore, including post-menarche adolescent girls for the assessment of menstrual knowledge before menarche could lead to the overestimation of menstrual knowledge of adolescent girls before menarche.

Previous studies on adolescent girls irrespective of their menstrual experience showed that menstrual knowledge depends on age adolescent girls. An increase in age leads to the onset of menarche which triggers adolescent girls to learn about menstruation. This means the onset of menarche is the intermediate variable between age and menstrual knowledge of adolescent girls. Perhaps, this might be the reason why, in our study, the age of pre-menarche girls was not associated with menstrual knowledge.

According to this study, menstrual knowledge of pre-menarche adolescent girls increased depends on their educational level. For a unit increase in school grade level, menstrual knowledge increased by $63.1 \%$. Parents' education and occupation had also associated with pre-menarche adolescent girls knowledge about menstruation. This is consistent with a study in Denpasar City (27) reports that the level of education and surrounding people, from whom they acquire information, influences menstrual knowledge of girls.

According to the present study, about one-fourth $25.9 \%$ pre-menarche adolescent girls were better prepared and $74.1 \%$ were poorly prepared for menarche. This finding lower than the finding of a study in 
Mexico (18) which reported $38 \%$ of adolescent females were badly prepared and $19 \%$ were well prepared for menarche. Similarly, 33\% of adolescent girls were not well prepared for menarche in Gambia (10), and in the Udupi district of Karnataka (21), 47.5\% had poor psychosocial preparation for menarche. This disagreement could be due to the study area's socio-cultural and demographic differences or variation in the measurement tools.

Menstrual knowledge of pre-menarche girls had a strong association with their preparedness for menarche. Having good menstrual knowledge increased the preparedness of pre-menarche girls to menarche by over 13-fold than poorly knowledgeable girls. Similarly, a study in Indonesia revealed (5) that lack of preparation for menarche of adolescent girls is due to insufficient menstrual knowledge.

As a cross-sectional study, this study has limitation in establishing causality based on the observed association between the covariates and the dependent variable. Not all adolescent girls attends school, so this study results can't be inferred to the total pre-menarche adolescent girls the area. Despite several measures were taken to minimize, due to sensitivity nature of menstruation the possibility of social desirability bias by study participants is unavoidable. Addressing this sensitive issue using quantitative data only without triangulation with qualitative approach is another limitations of this study. Therefore, further research with mixed study design approach is recommended to exhaustively explore those sensitive variables related to menstrual knowledge and preparedness to menarche among pre-menarche adolescent girls.

\section{Conclusions}

According to this study, menstrual knowledge and preparedness to menarche were very low. The cause and origin of menstrual blood were common misconceptions among pre-menarche adolescent girls. Maternal education, fathers' occupation, and girls' school grade level had an independent association with pre-menarche adolescent girls' menstrual knowledge. The level of preparedness to menarche was also highly dependent on girls' menstrual knowledge. Thus, adolescent girls should acquire accurate and adequate knowledge as early as possible; schools should deliver age-appropriate menstrual information.

\section{List Of Abbreviations}

LMICs: Low and Middle Income countries

\section{Declarations}

\section{Ethics approval and consent to participate}

Ethical clearance was obtained from the Ethical Review Committee of Debre Berhan University. A letter of support written to participating Woreda was obtained from the zonal health office. Permission letter was also obtained from the Woreda education office and each selected school. Permission to proceed with the study was obtained from each participating school following an explanation of the objective of the study 
for school directors. Data was collected after each study participants were adequately informed about the purpose, benefits, and risks of the study and their right to discontinue or refuse to participate in the study. Written consent was obtained from $\geq 15$ years old study participants, and for those $<15$ years old verbal consent from parents and assent from participants was obtained. For confidentiality purpose, the names of participants and other personal identifiers related questions were excluded in the questionnaire. The collected data were stored in a safe place where no one can access it except the research teams.

\section{Consent for publication}

Not applicable

\section{Availability of data and materials}

The datasets used and/or analyzed during the current study are available from the corresponding author on reasonable request.

\section{Competing interests}

The authors declare that they have no competing interests

\section{Funding}

The authors received no specific funding for this work.

\section{Author Contributions}

$A B$ designed the investigation, carried out the data analyses, interpreted the results and drafted the manuscript; MA facilitated the data collection, interpreted the results, and reviewed and revised the manuscript. All authors read and approved the final manuscript.

\section{Acknowledgment}

Authors acknowledge the Woreda Education Offices and school directors for their consent and assistance. Most of all we are sincerely grateful for the study participants and data collectors for their full involvement in the data collection process. We thank Debre Berhan University for material and financial support.

\section{References}

1. Coast E, Lattof SR. Young adolescent girls' knowledge of menstruation and puberty: A rapid evidence review: Gender and Adolescence: Global Evidence; 2018.

2. Geertz A, lyer L, Kasen P, Mazzola F, Peterson K. An opportunity to address menstrual health and gender equity: FSG; 2016.

3. MoH. Ethiopia school health program framework. Addis Ababa, Ethiopia: Ministry of Health; 2017. 
4. FMoH. Adolescent and youth reproductive health: Blended learning module for the health extension program.

5. UNICEF. Menstrual hygiene management in Indonesia: Understanding practices, determinants and impacts among adolescent school girls. UNICEF INDONESIA; 2015.

6. Chandra-Mouli V, Patel SV. Mapping the knowledge and understanding of menarche, menstrual hygiene and menstrual health among adolescent girls in low- and middle-income countries. Reproductive Health. 2017; 14:30.

7. Tamiru S. Girls in control: Compiled findings from studies on menstrual hygiene management of schoolgirls. 2014.

8. Karki KB, Poudel PC, Rothchild J, Pope N, Bobin NC, Gurung Y, et al. Scoping review and preliminary mapping: Menstrual health and hygiene management in Nepal. 2017:1-99.

9. Gupta P, Gupta J, Singhal G, Meharda B. Knowledge and practices pertaining to menstruation among the school going adolescent girls of UHTC/RHTC area of Government Medical College, Kota, Rajasthan. Int J Community Med Public Health. 2018; 5(2):652-6.

10. Shah V, Nabwera HM, Sosseh F, Jallow Y, Comma E, Keita O, et al. A rite of passage: a mixed methodology study about knowledge, perceptions and practices of menstrual hygiene management in rural Gambia. BMC Public Health. 2019; 19:277.

11. Sidi I, Salifou K, Obossou A, Hounkpatin B, Hounkponou A, Aguemon CT, et al. Knowledge, Attitudes and Practices of High School Students with Menarche in Parakou/Benin in 2014. Clinics Mother Child Health. 2014; 13:219.

12. Gultie T, Hailu D, Workineh Y. Age of Menarche and Knowledge about Menstrual Hygiene Management among Adolescent School Girls in Amhara Province, Ethiopia: Implication to Health Care Workers \& School Teachers. PLoS ONE. 2014; 9(9):e108644.

13. Belayneh Z, Mekuriaw B. Knowledge and menstrual hygiene practice among adolescent school girls in southern Ethiopia: a cross-sectional study. BMC Public Health. 2019; 19:1595.

14. Tegegne TK, Sisay MM. Menstrual hygiene management and school absenteeism among female adolescent students in Northeast Ethiopia. BMC Public Health. 2014; 14:1118.

15. Burrows A, Johnson S. Girls' experiences of menarche and menstruation. Journal of Reproductive and Infant Psychology. 2005; 23(3):235-49.

16. Chang Y-T, Chen Y-C, Hayter M, Lin M-L. Menstrual and menarche experience among pubescent female students in Taiwan: implications for health education and promotion practice. Journal of Clinical Nursing. 2009; 18:2040-8.

17. FMoH. Menstrual hygiene management policy and implementation guideline. Addis Ababa: Ministry of Health; 2016.

18. Marvan L, Alcala-Herrera V. Age at menarche, reactions to menarche and attitudes towards menstruation among Mexican adolescent girls. J Pediatr Adolesc Gynecol. 2014; 27:61-6. 
19. Setyowati, Rizkia M, Ungsianik T. Improving female adolescents' knowledge, emotional response, and attitude toward menarche following implementation of menarcheal preparation reproductive health education. Asian/Pacific Island Nursing Journal. 2019; 4(2):84-91.

20. Anchebi TH, Fite RO, Shiferaw BZ, Abeya SG. Predictors of knowledge towards menstruation in Ethiopia. Diversity and Equality in Health and Care. 2018; 15(5):241-6.

21. Salins CC, D'souza A, Nayak MG. knowledge, perception and psychosocial preparedness for menarche among adolescent girls of Udupi District, Karnataka. Indian journal of public health research \& development. 2018; 9(9):13-7.

22. Michael J, Iqbal Q, Haider S, Khalid A, Haque N, Ishaq R, et al. Knowledge and practice of adolescent females about menstruation and menstruation hygiene visiting a public healthcare institute of Quetta, Pakistan. BMC Women's Health. 2020; 20(4):8.

23. A K, S K. Knowledge, Attitude and Socio-cultural Beliefs of Adolescent Girls towards Menstruation. J Nepal Paediatr Soc. 2016; 36(1):42-9.

24. S C, S G, S Y. Premenarche information and dysmenorrhea in young girls. Insights in Reproductive Medicine. 2017; 1(2):6.

25. Shoor P. A study of knowledge, attitude, and practices of menstrual health among adolescent school girls in urban field practice area of medical college, Tumkur. Indian J Health Sci Biomed Res. 2017; 10:249-55.

26. Kitesa B, Getahun T, Wako K. Assessment of Knowledge and Practice of Adolescent In-School Girls Towards Menstrual Hygiene Management and Determining Factors in Lucy Village of Ethiopian Great Rift Valley, 2016. International Journal of Immunology. 2016; 4(6):52-63.

27. Diaris NM, Listyowati R, Januraga PP. Readiness of girls aged 10-12 years for an early menarche: a transtheoretical model of behavioral change analysis. Public Health and Preventive Medicine Archive. 2017; 5(1):55-61. 